\title{
Medicolegal Forum: The Apgar Score
}

Gilbert I. Martin, MD

The Apgar score has continued to emerge as an important parameter in the medical-legal arena. That is, it is often used to prognosticate future neurological compromise and blame it on inappropriate obstetrical and/or neonatal care. The following poem, written in 1989, remains pertinent today. For the first five individuals who submit a letter to the editor regarding the Apgar Poem, I will send that person an Apgar Stamp from my own personal collection.

"For the first five individuals who submit a letter to the editor regarding the Apgar Poem, I will send that person an Apgar Stamp from my own personal collection."

Virginia Apgar, in '53,

was practicing anesthesiology.

She said to colleagues with great frustration,

"The newborn babe needs observation.

Correct assessment with more attention,

leads to appropriate intervention.

If we pick numbers that seem to jive,

can this predict who will survive?"

A scale devised that very year

was clinically oriented and did seem fair.

Heart rate, reflex irritability, and muscle tone

were numbered singly, each one alone.

Respiratory effort and color too,

Hence, the score-but what to do?

Measured at minutes, one, five, and ten, Instructed what to do and when---
Problems arose with such a roar,

Who should assign this "Apgar Score"?

The obstetrician called numbers high, for perfect babies would not die.

The pediatrician, not wanting blame, called numbers low-this was a shame.

This left the task to the poor nurse,

who often found the job a curse.

Five clinical signs made up the score,

but in reality, there were several more.

The obstetricians yelled and booed,

wailing that they'd soon be sued.

Pediatricians countered, "Don't be afraid,

Asphyxia's a term that soon will fade."

And then some babies born premature

could not be measured with the score.

Cord $\mathrm{pH}$, gestational age

Made the number a poor gauge.

Faulty recall, postdated noting

had the lawyers really gloating.

Potential help for this condition

mimics Olympics competition:

Skaters, gymnasts, and divers, too,

are all assigned a score by few.

A special team of five or more

could redefine the Apgar score.

In-house, on-call for deliveries, 
their Apgar scores would surely please.

\section{A 3,4 , or 7.1 ,}

hold up your cards-we've just begun.

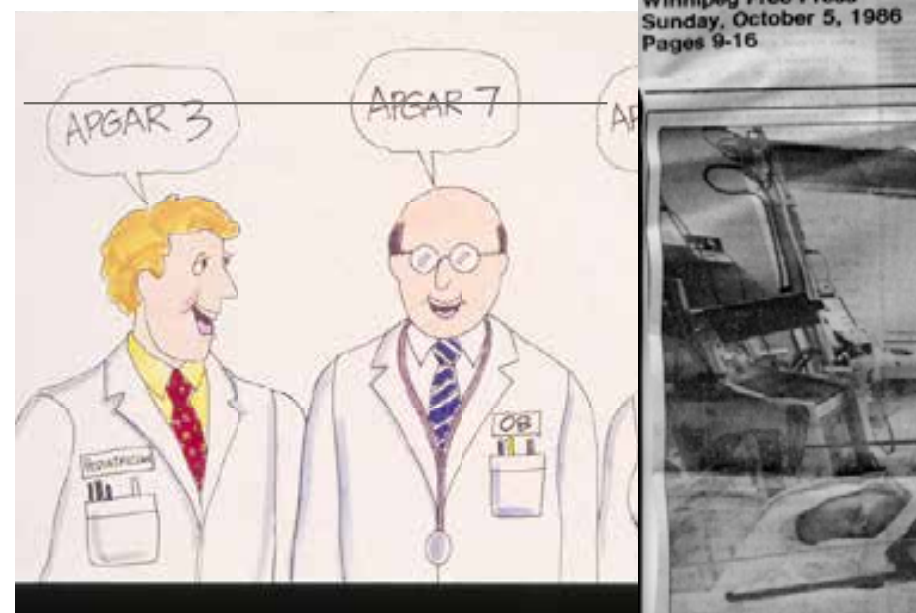

Three and one-half million births a year,

Who will fund a cost so dear?

Perhaps the answer is soporific,

as we attempt to be scientific.

Encourage closer observation,

adapt a score without inflation.

Modify existing terms-

We've opened up a can of worms.

THE PERINATE

Disclosure: There are no reported conflicts.

$$
\text { NT }
$$

Corresponding Author

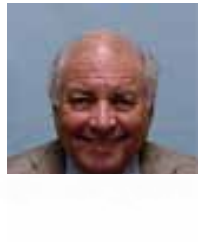

Gilbert I Martin, MD, FAAP

Division of Neonatal Medicine

Department of Pediatrics

Professor of Pediatrics

Loma Linda University School of Medicine

Email: gimartin@llu.edu

Office Phone: 909-558-7448

\section{New subscribers are always welcome!} NEONATOLOGY IQDAY

To sign up for a free monthly subscription, just click on this box to go directly to our subscription page

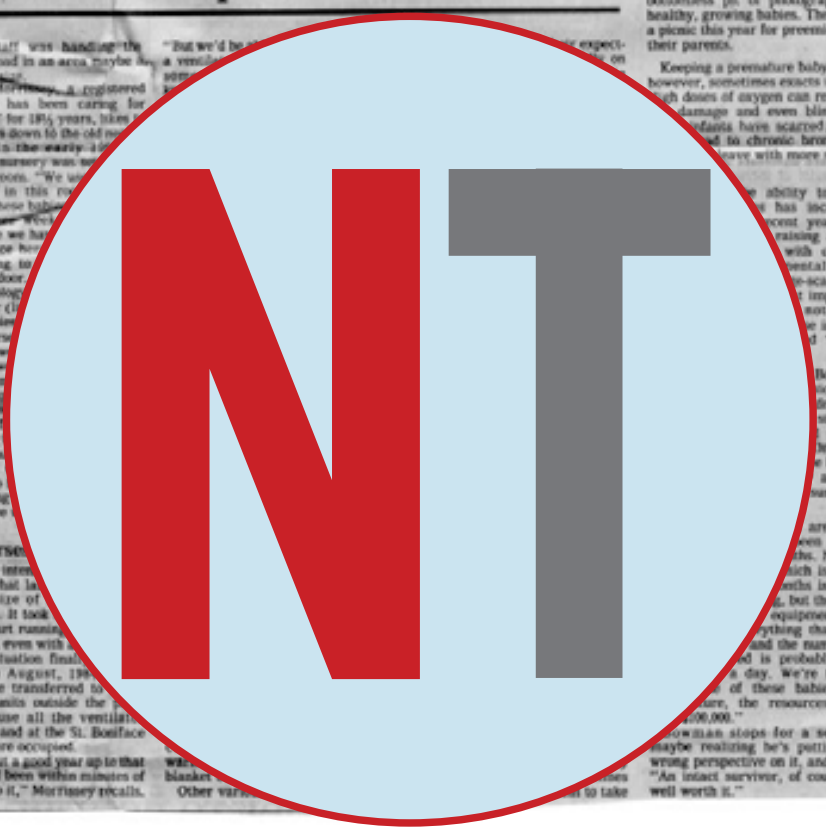

Sign up for free membership at 99nicu, the Internet community for professionals in neonatal medicine. Discussion Forums, Image Library, Virtual NICU, and more..."

www.99nicu.org 